\title{
The Issues of the Evaluation System of Korean Long-term Care Facilities and Measures for Improvement
}

\author{
Yun-Jeong Kim, Sang-Jin Lee
}

\begin{abstract}
The objective of this study was to conduct a FGI with the administrative directors of nursing homes that will be subject to evaluation in 2018 and the external evaluators, to identify issues with the current evaluation system and measures for improvement. An analysis of the FGI led to 15 sub-themes and 4 essential themes is as follows. The four essential themes were "distrust in the evaluation system," "evaluation indexes that make want to give up on the evaluation," "lack of preparation for on-site evaluation" and "lack of evaluation indexes to measure service quality." As an improvement measure, First, a third-party evaluation system or a multi-layered evaluation system can be adopted to provide an objective review. Second, a multi-layered evaluation system will also help shift the evaluation away from a focus on document systems towards securing better quality in services for the elderly residents living at these types of facilities.
\end{abstract}

Keywords : Evaluation system, Evaluation indexes, FGI, Colaiszzi method, Third-party evaluation system, Multi-layered evaluation system.

\section{INTRODUCTION}

$\mathrm{T}_{\mathrm{h}}$ his discussion begins with the distinction that long-term care institutions for the elderly in Korea are also referred to as nursing homes. With the adoption of long-term nursing insurance policies for the elderly in 2008, nursing homes have developed into a concept of medical protection facilities for the elderly. The long-term nursing insurance policy is operated in three areas. The first area includes services that are tasked with the use of welfare tools. This is a type of service that purchases or leases medical equipment, such as wheelchairs or air mats for the elderly who had been diagnosed with a nursing grade and who lives at home. The second area involves at-home nursing services. In this case, nursing therapists or nurses make house visits to offer long-term care, nursing, day care and short-term protection. Third, the elderly can be admitted to a nursing facility to receive medical, protective or daily services. Among these three areas, this study focuses on the long-term nursing institutions. The evaluation system for nursing facilities for the elderly which started in 2009, has now marked its 6th

Revised Manuscript Received on July 22, 2019.

* Correspondence Author

Yun-Jeong Kim*, Department of Health, Counseling and Welfare, Hanseo University, Seosan City, Republic of Korea. Email: twoyun21@hanmail.net

Sang-Jin Lee*, Department of Health, Counseling and Welfare, Hanseo University, Soesan City, Republic of Korea. Email: welfare-i@hanmail.net evaluation as of 2018, and currently reviews 4,763 facilities [1].

In this respect, an evaluation is a judgment of a person, the value or degree of a thing based on a certain identified or established criteria. It requires analysis, judgment and assessment on the status of the object or the review [2]. The evaluation results of 2018 are scheduled to be made public on the website of the long-term nursing insurance for the elderly, and the statistics showing the current status of long-term nursing institutions. The absolute evaluation grades (A, B, C, $\mathrm{D}, \mathrm{E})$ of all long-term nursing institutions that underwent evaluation will be disclosed. Grade A long-term nursing institutions that are under the top $20 \%$ for each facility size will receive additional subsidies, while long-term nursing institutions that receive the lowest grade (Grade E) have spontaneous evaluations scheduled [1].

Interest in the evaluation system for long-term nursing institutions and on-site evaluation has continuously been the subject of review in academia [3], whereas the awareness of the importance of the evaluation index is a high priority for researchers [4]. There are current studies [5-9] on the development of evaluation indexes and their improvements, perception of the importance of evaluation indexes, application of evaluation results and evaluation systems that have value to be reviewed in this area, to offer advice on how to manage better systems in this case for improved care models at nursing institutions.

Preceding studies have roughly two categories of issues. First, studies on evaluation indexes include factors such as regarding the operation of the institution, the environment of the facilities and quality of services, but it is noted that there is a lack of studies that include the quality of life for the admitted senior citizens or the criteria used for the selection of appropriate facilities. Second, there are issues related to the review of on-site evaluations of the institution. One of the issues with the evaluation method is that it is usually focused around the documents drafted by the institution, leading to undermined credibility and increased workload for the institution [10]. This situation has not changed for up to the year 2018. Next, it is of interest to note the issue of the evaluator, and how evaluations are affected by these concerns. Up until 2015, the National Health Insurance Board that operates the long-term nursing insurance policy for the elderly had conducted on-site evaluations.

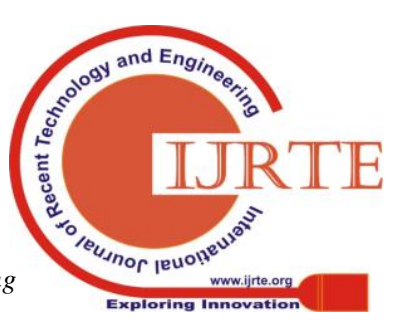


This has led to criticism that the results of on-site evaluation were being used predominantly for administrative surveys. Some people have also criticized that the board employees are not experts as they have no experience in having provided long-term nursing services [11].

As a result, there have been three changes in the processing of the 2018 evaluation. First, the evaluation indexes have been streamlined. The 88 indexes have been reduced to 48 (and 46 for joint families for nursing the elderly). Second, the expertise of the evaluators has been reinforced. One external evaluator who has experience in operating such a facility or from the academia is now included to make up a standing three-person team for on-site evaluation. Third, a satisfaction survey was also included with the guardians of beneficiaries as the respondents [1].

As such, there is a need to review any issues or implications of the changed evaluation system, and how they are seen by the head of the facility and external evaluators. In this study, an in-depth interview through an FGI will be conducted with the head of nursing homes and external evaluators for 2018, in an effort to identify issues with the current evaluation system and measures for improvement.

\section{METHODS}

The subjects of the study are administrative directors of facilities that underwent the 2018 evaluation for nursing homes and external evaluators. A total of seven administrative directors of facilities, with 1-2 people per evaluation grade for 2015 were recruited for the study. For external evaluators, four people who have handled external evaluation work in Seoul, Gyeonggi, Chungnam and Gyeongnam were recruited.

In this case, FGI with heads of facilities was conducted for two hours in the office of the researcher on September 12, 2018. For external evaluators, since they came from all across the country, the interview was conducted for three hours at Seoul Station on October 5, 2018. During the interview, there were questions such as "What do you think of the current evaluation method for nursing facilities for the elderly?" "What do you think of the role of the external evaluator?" and "What are the areas needing improvement in terms of evaluation indexes or on-site evaluation methods?" were discussed. After explaining the objectives of the study, the consent was sought on recording the interview. The recording was then made into a transcript for further analysis.

To analyze the transcripts, the method of Colaizzi a humanities-focused psychology who was influenced by Merleau-Ponty, was used [12]. He extracted significant sentences or phrases from the statements made by participants and from them made general and abstract statements for review. After categorizing these transcripts by theme, the essential structure of the experience was stated. There are seven analysis stages in the method. In this study, the seven stages of Colaizzi presented by [12] was applied.

\section{RESULTS AND DISCUSSION}

An analysis of the FGI led to 15 sub-themes and 4 essential themes is as follows. The four essential themes were "distrust in the evaluation system," "evaluation indexes that make want to give up on the evaluation," "lack of preparation for on-site evaluation" and "lack of evaluation indexes to measure service quality." The essential themes, sub-themes and identified improvement evaluation are shown in Table 1 $\sim$ Table 4.

\section{A. Distrust in the evaluation system}

In this case, the factors of Distrust in the evaluator, Distrust in the evaluation objectives, Lack of enforceability in the evaluation result, Size of the facility, regional characteristics and characteristics of the elderly are not taken into account, and therefore were grouped to the "Distrust in the evaluation system."

In order to solve this "distrust of evaluation system," we propose the following three improvement measures. The first is the introduction of a third-party evaluation system such as used in Japan and the introduction of a multi-tiered evaluation system. In other words, the establishment of a third institution that specializes in performing a professional evaluation, such as in Japan, is responsible for the evaluation and consulting from the agency, or introducing a multi-tiered evaluation system to evaluate the administrative aspect and the service aspect of the institution. I suggest urgency be considered in this case, to resolve the relevant issues. Second, it reinforces the incentive for the decision on the evaluation results. Even now, in the event that or if the rating is the lowest, there are no other sanctions, and therefore the effort and motivation to receive a good or deemed satisfactory evaluation is in that instance reduced. For example, if the rating is low, there may be the need to reduce the number of people by $10 \%$ or $20 \%$, or have the evaluation be re-evaluated the next year, or if the lowest rating is more than 2 , more powerful measures such as institutional closures will be needed to be considered in that case. Finally, it is the introduction of a differential evaluation system in accordance with the present circumstances and circumstances of the organization. At present, there is a tendency to grade regardless of the size of the institution, but it is possible to classify large institutions by competition among large institutions, and small institutions by means of identifying and determining competition among small institutions. 
Table 1: Distrust in the evaluation system

\begin{tabular}{|c|c|c|c|}
\hline Essential Theme & Sub-Theme & Formed Meaning & $\begin{array}{c}\text { Improvement } \\
\text { Direction }\end{array}$ \\
\hline \multirow{4}{*}{$\begin{array}{l}\text { Distrust in the } \\
\text { evaluation } \\
\text { system }\end{array}$} & $\begin{array}{l}\text { Distrust in the } \\
\text { evaluator }\end{array}$ & $\begin{array}{l}\text { Distrust in the National Health Insurance Board; } \\
\text { Hierarchy between the National Health Insurance } \\
\text { Board and long term nursing facilities; authoritarian } \\
\text { attitude of the Board, lack of expertise by the } \\
\text { evaluators. }\end{array}$ & $\begin{array}{l}\text {-Introduce a third party } \\
\text { evaluation system } \\
\text {-Introduce a } \\
\text { multi-layered } \\
\text { evaluation system }\end{array}$ \\
\hline & $\begin{array}{l}\text { Distrust in the } \\
\text { evaluation } \\
\text { objectives }\end{array}$ & $\begin{array}{l}\text { A negative perception that the evaluation is done for } \\
\text { administrative surveys; A view that links everything } \\
\text { associated with the facility to evaluations, the } \\
\text { intention to look into the nitty gritty details of the } \\
\text { institution through the evaluation, the perception of } \\
\text { the head of institution that sees the extra points and } \\
\text { monitoring policies as a way to supervise and control } \\
\text { the institution }\end{array}$ & \\
\hline & $\begin{array}{l}\text { Lack of } \\
\text { enforceability in } \\
\text { the evaluation } \\
\text { results }\end{array}$ & $\begin{array}{l}\text { There are not enough incentives or disincentives to } \\
\text { use the evaluation results for further progress, } \\
\text { leading to low confidence in the evaluation itself. }\end{array}$ & $\begin{array}{l}\text { Reinforcement of } \\
\text { disincentives based on } \\
\text { evaluation results }\end{array}$ \\
\hline & $\begin{array}{l}\text { Size of the facility, } \\
\text { regional } \\
\text { characteristics and } \\
\text { characteristics of } \\
\text { the elderly are not } \\
\text { taken into account }\end{array}$ & $\begin{array}{l}\text { Joint families where the elderly are nursed, smaller } \\
\text { facilities and facilities in rural areas are not taken } \\
\text { into account for their specifics during evaluation }\end{array}$ & $\begin{array}{l}\text { Adopt a differentiated } \\
\text { evaluation system based } \\
\text { on the size and } \\
\text { characteristics of the } \\
\text { facility }\end{array}$ \\
\hline
\end{tabular}

\section{B. Evaluation indexes that made the evaluation abandon}

In this situation, the relevant issue concerns the information gaps in the evaluation indexes, the ambiguous evaluation indexes which have a wide range of interpretation, the unrealistic evaluation indexes difficult to supervise and supervise by the institution, and the unfairness of the evaluation points were grouped to the "evaluation indexes that made the evaluation abandon."

To solve these problems, we propose the following two solutions. The first is to initiate an advanced announcement and training of the required evaluation index manual. In particular, the evaluators and the evaluators should gather together and be educated about the evaluation indicators to be considered part of a more transparent system, and to be therefore determined as fair. The second is the restructuring of the evaluation index or the revision of the evaluation index. This step is necessary to eliminate ambiguous expressions in qualitative evaluation among evaluation indexes, or to clarify explanation of evaluation indexes. In addition, it is suggested that the evaluation indexes which are difficult to supervise and supervise by institutions, should alleviate the burden of the institutions through a merging and unification of the applicable systems, and it is necessary to prioritize the application of the upper law through careful examination of laws or laws that conflict with each other in that case.

Table 2: Evaluation indexes that made the evaluation abandon

\begin{tabular}{|c|c|c|c|}
\hline Essential Theme & Sub-Theme & Formed Meaning & Improvement Direction \\
\hline \multirow{3}{*}{$\begin{array}{l}\text { Evaluation } \\
\text { indexes that } \\
\text { made the } \\
\text { evaluation } \\
\text { abandon }\end{array}$} & $\begin{array}{l}\text { Information gap in } \\
\text { the evaluation } \\
\text { indexes }\end{array}$ & $\begin{array}{l}\text { Information gap between institutions that are active } \\
\text { in the association and those that are not; Manual for } \\
\text { the evaluator is different from the manual for } \\
\text { institutions or facilities }\end{array}$ & $\begin{array}{l}\text { Advanced notification and } \\
\text { education on evaluation } \\
\text { indexes and manuals }\end{array}$ \\
\hline & $\begin{array}{l}\text { Ambiguous } \\
\text { evaluation indexes }\end{array}$ & $\begin{array}{l}\text { Unclear definition of 'expertise' in the operating } \\
\text { committee's index for expertise; ambiguity in } \\
\text { defining psychological indexes (unclear as to what } \\
\text { "currently trying" means). } \\
\text { This makes it difficult to prepare for the evaluation. }\end{array}$ & \multirow{2}{*}{$\begin{array}{l}\text { Restructuring of the } \\
\text { evaluation indexes }\end{array}$} \\
\hline & $\begin{array}{l}\text { Unrealistic } \\
\text { evaluation indexes } \\
\text { that are difficult to } \\
\text { supervise }\end{array}$ & $\begin{array}{l}\text { Preparation for the evaluation is difficult as the } \\
\text { indexes are unrealistic, e.g. policies for } \\
\text { commissioned doctors, issues concerning urine tubes, } \\
\text { recording of drug administration times }\end{array}$ & \\
\hline
\end{tabular}




\begin{tabular}{|l|l|l|}
\hline & $\begin{array}{l}\text { Unfair evaluation } \\
\text { scores }\end{array}$ & $\begin{array}{l}\text { Same index as of 2015 but the scores are different; } \\
\text { Even a single item lacking leads to zero points. } \\
\text { A conflict between the evaluation indexes and other } \\
\text { laws make the scoring system unfair. }\end{array}$ \\
\hline
\end{tabular}

\section{Lack of evaluation conditions}

The lack of confidence in the expertise of the evaluator, the problem of the external evaluator's service quality evaluation system, the institutional work paralysis due to the late announcement of the evaluation schedule, and the lack of standardized document format were bound to be seen and categorized as a "lack of evaluation conditions."

We propose two improvement measures to solve the issue of concerns surrounding the current evaluation condition. The first recommendation is securing the reliability of external evaluators. Currently, there is one employee of the National Pension Service, one person who has experience in facility operation or one external evaluator in the academy, and conducts on-site evaluation on a set of three. These evaluators are composed of the National Pension Service and one academy, and one reviewer who has experience in facilities operation but who does not currently operate the facilities, thereby improving the professionalism of the academy and the practical experience of the field. Additionally, it can be said that there is a need to secure trust from the elderly long-term care institutions. Second, it suggests that the field evaluation system should be reorganized to become more effective. The evaluation schedule should be announced at least 3-4 weeks in advance, and the National Pension Service or the Ministry of Health and Welfare will provide the standardized documents to resolve the difficulty of preparation for the scheduled evaluation.

Table 3: Lack of evaluation conditions

\begin{tabular}{|c|c|c|c|}
\hline $\begin{array}{l}\text { Essential } \\
\text { theme }\end{array}$ & Sub-theme & Formed meaning & Improvement direction \\
\hline \multirow{4}{*}{$\begin{array}{l}\text { lack of } \\
\text { evaluation } \\
\text { conditions }\end{array}$} & $\begin{array}{l}\text { lack of confidence in the } \\
\text { expertise of the evaluator }\end{array}$ & $\begin{array}{l}\text { Evaluator lacks on-site experience; Scores } \\
\text { vary depending on the evaluator's } \\
\text { interpretation and judgment }\end{array}$ & \multirow[b]{2}{*}{$\begin{array}{l}\text { Improve trust in external } \\
\text { evaluators }\end{array}$} \\
\hline & $\begin{array}{l}\text { problems of the external } \\
\text { evaluator's service quality } \\
\text { evaluation system }\end{array}$ & $\begin{array}{l}\text { Indexes for employee interviews need to be } \\
\text { memorized; Difficulty in counseling for the } \\
\text { elderly who have cognitive issues; Low } \\
\text { scores on service quality when external } \\
\text { evaluators are involved. }\end{array}$ & \\
\hline & $\begin{array}{l}\text { institutional work paralysis } \\
\text { due to the late announcement } \\
\text { of the evaluation schedule }\end{array}$ & $\begin{array}{l}\text { Leads to a situation where an evaluation } \\
\text { within one year is anxiously anticipated. }\end{array}$ & \multirow{2}{*}{$\begin{array}{l}\text { Refinement of the on-site } \\
\text { evaluation system }\end{array}$} \\
\hline & lack of standardized document & $\begin{array}{l}\text { Small scale facilities do not have the right } \\
\text { forms and thus need to purchase them }\end{array}$ & \\
\hline
\end{tabular}

\section{Lack of evaluation indexes for evaluation of service quality}

The lack of evaluation indicators to guarantee consumer's decision-making rights, unnecessary indicators that are not suitable for periodic evaluation and the overwork due to the upgrading of evaluators and documents were tied to "lack of evaluation indexes for evaluation of service quality."

In order to solve the problems related to these evaluation indexes, we propose two major improvements. The first is the introduction of a care manager system as is used widely in Japan. In the case of care managers in Japan, the elderly and their families, who are consumers of long-term care institutions, are recommended to the most appropriate institutions for their needs to manage elder care requirements. In Korea, it is necessary to meet the needs of the elderly and improve the quality of life through the introduction of care managers. Second, the indicators for the evaluation of the quality of services and the introduction of a multi-tiered evaluation system need to be discussed. In other words, the indicators that can be evaluated through the National Pension Service or the administrative evaluation through the multi-tiered evaluation system, are thereby deleted or carried out separately in the first step. In actual evaluation of long-term care institutions for the elderly, the evaluation index results are suggesting the need to make adjustments. 
Table 4: Lack of evaluation indexes for evaluation of service quality

\begin{tabular}{|c|c|c|c|}
\hline Essential Theme & Sub-Theme & Formed Meaning & Improvement Direction \\
\hline \multirow{3}{*}{$\begin{array}{l}\text { Lack of } \\
\text { evaluation } \\
\text { indexes for } \\
\text { evaluation of } \\
\text { service quality }\end{array}$} & $\begin{array}{l}\text { Lack of evaluation } \\
\text { indexes to guarantee } \\
\text { consumers' } \\
\text { decision-making rights } \\
\end{array}$ & $\begin{array}{l}\text { Lack of evaluation indexes to measure } \\
\text { service quality means consumer rights for } \\
\text { selecting facilities based on evaluation } \\
\text { grades are not guaranteed. }\end{array}$ & $\begin{array}{l}\text { Adopt a care manager system like } \\
\text { that of Japan }\end{array}$ \\
\hline & $\begin{array}{l}\text { Unnecessary indexes } \\
\text { that are not suitable for } \\
\text { periodic evaluation }\end{array}$ & $\begin{array}{l}\text { Excessive number of evaluation indexes } \\
\text { that are redundant }\end{array}$ & $\begin{array}{l}\text {-Evaluation indexes need to be } \\
\text { restructured to measure service } \\
\text { quality } \\
\text {-Adopt a multi-layered evaluation } \\
\text { system }\end{array}$ \\
\hline & $\begin{array}{l}\text { Overwork due to the } \\
\text { upgrading of evaluators } \\
\text { and documents }\end{array}$ & $\begin{array}{l}\text { Through similar evaluation methods over } \\
\text { the past decade the evaluator and } \\
\text { paperwork have been updated but service } \\
\text { quality is not measured and only work } \\
\text { load has increased }\end{array}$ & \\
\hline
\end{tabular}

\section{CONCLUSION}

The objective of this study was to conduct a FGI with the administrative directors of nursing homes that will be subject to evaluation in 2018 and the external evaluators, to identify issues with the current evaluation system and measures for improvement. To that end, a FGI was conducted on seven administrative directors of nursing homes, and with four external evaluators in September and October of 2018. The findings can be summarized as follows.

First, the issue of the evaluator needs to be addressed. At present, the National Health Insurance Board which runs the long-term nursing insurance for the elderly evaluates facilities. This leads to higher efficiency in evaluation but the focus is excessively on supervision. There are no checks and balances to rein in the Board, in this circumstance. To address this issue, a third-party evaluation system or a multi-layered evaluation system can be adopted to provide an objective review. The former has a third-party institution objectively conduct a qualitative evaluation from a neutral stance. The evaluation for social welfare facilities in Korea and the quality management system for long-term nursing homes in Japan use such a system. As for Japan, a multi-layered quality control is also performed, by the careful monitoring and auditing from the administrative bodies, financial audits by accountants and tax authorities and social welfare councils. An evaluation is performed in multiple aspects to secure efficiency and effectiveness. As for Korea, unlike the 2015 evaluation, the 2018 evaluation has adopted a system of "evaluation by the Board + joint evaluation with external experts" but given that the external evaluator has a limited authority, the issue has not been completely overcome.

Second, in applying the evaluation results, there is not a procedure in place to force an improvement in service quality for nursing homes that have been given a lower grade. Of course, there are laws that require spontaneous evaluation on the lowest grade nursing homes starting in 2016, but this type of spontaneous evaluation cannot be seen as a disincentive originating from the previously identified negative evaluation results. Therefore, unless there is a stronger corrective measure, the current evaluation system may be of no use, or of limited use in this case.

Third, the lack of detailed education on the evaluation index manual has led to an information gap in some cases. When the evaluation schedule is made available only a week before the evaluation, the normal operations of nursing homes are disrupted. In those cases where document forms are not standardized, it may be the case of leading to smaller scale institutions to purchase these types of standardized template forms from external sources. Therefore, efforts must be made to close the information gap through education where the evaluator and evaluate join together to collaborate for solutions, and to this end the evaluation schedules must be announced at least two months in advance to leave room for preparation of all parties to participate in the process. Administrative support should also be provided, including standardizing document formatting which will assist to lessen the workload currently in place in smaller institutions.

Lastly, no indices are currently available to measure the service quality. In 2018 a satisfaction survey was conducted on the families of admitted senior citizens, but there is still skepticism as to whether this survey can lead to improved service quality. Therefore, a new model of care is required, such as Japan's care manager clinical model is needed to improve patient care outcomes going forward. A multi-layered evaluation system will also help shift the evaluation away from a focus on document systems towards securing better quality in services for the elderly residents living at these types of facilities.

\section{ACKNOWLEDGMENT}

This work was supported by the Ministry of Education of the Republic of Korea and the National Research Foundation of Korea (NRF-2017S1A5A2A01026950). 


\section{REFERENCES}

1. NHIS, 2018 Long-term care institution periodic evaluation plan, NHIS, 2018. http://www.nhis.or.kr/bbs7/boards/B0039/25313

2. Y. S. Lee, D. Jaegal, J. H. Kim, H. R. Kim, G. H. Sim, K. S. Yun and H. S. Park, Government performance management and evaluation system: focused on case of major developed countries Deayoung Press, Seoul Korea, 2016. pp. 247

3. H. S. Choi, E. Y. Seo, C. S. Lee, J. M. Won, A study on development of eh evaluation criteria for elderly care facilities, Journal of the Korea Real Estate Analysts Association, vol. 18, no. 4, 2012, pp. 131-147.

4. Y. K. Lee and J. S. Kim, The Perspectives Analysis of Evaluation Indicators for Social Welfare Facilities, Korean Public Management Review, vol. 25, no. 1, 2011, pp. 33-56.

5. H. J. Kwon, The New-institutionalism perspective for long-term care service evaluation system, Korean Journal of Social Welfare, vol. 66, no. 2, 2014, pp. 5-29

6. W. D. Sun, Results and implications of long-term care facilities for the elderly, Health•Welfare Issue \& Focus, vol. 260, 2014, pp. 1-8.

7. D. S. Lee, Regular evaluation and analysis of elderly care facilities, Social Enterprise \& Policy Studies, Vol. 5, no. 1, 2015, pp. 53-102.

8. T. S. Jun and K. H. Jun. A Study perception on the importance and applicability of the evaluation indexes of long-term care institution employees, Korean Journal of Care Management, vol. 8, 2013, pp. 43-73.

9. M. M. Choi, J. G. Lim, S. K. Kim and K. S. Kim, What did social workers experience and what do they want for the evaluation system of social welfare facilities? Journal of Korean Social Administration, vol. 17, no. 3, 2015, pp. 1-26.

10. M. J. Lee, A Study on measurement issues of the quality of long-term care services for older adults, Social Welfare Policy, vol. 38, no. 1, 2011, pp. 141-166.

11. J. K. Kim, Institutional evaluation of long-term care insurance for the elderly-focused on supplier perspective, Journal of Social Welfare Management, vol. 3, no. 2, 2016, pp. 277-290.

12. P. Colaizzi, Psychological research as the phenomenologist views it. Existential Phenomenological Alternatives for Psychology, 1978, pp. 48-71.

\section{AUTHORS PROFILE}

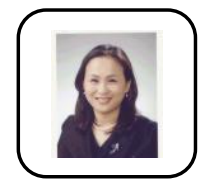

Yun-Jeong Kim, Ph.D., Ewha Womans University Professor, Hanseo University

Chairman of health and welfare department of Hanseo University, South Korea

Advisory Professor in Chungnam-do, Seosan-si, Hongseong-gun, Seosan-si, Dangjin-si, etc.

Publication: Gerontology, The elderly welfare, etc.

Research Areas: Elderly Care, Elderly Suicide, Elder Abuse, Old Age Studies, Family Relations, etc.

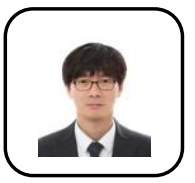

Sang-Jin Lee, Ph.D., Hanseo University Adjunct Professor, Hanseo University Research Areas: Elderly Welfare, Long-term Care, Social Welfare, etc. 